\title{
FAKTOR - FAKTOR YANG MEMPENGARUHI PURCHASE INTENTION PRODUK PRIVATE LABEL SIRUP INDOMARET DI JAKARTA
}

\author{
Edwin Rommel Yudistira \\ Program Studi Magister Manajemen Universitas Tarumanagara \\ edwinromme192@gmail.com
}

Masuk : 05-07-2019, revisi : 22-08-2019 diterima untuk diterbitkan : 23-08-2019

\begin{abstract}
Indonesia's retail business has grown with the increasing number of existing retailers. The presence of this retailer gave rise to private label products in Indonesia. Private labels are one of the retailer's strategies to be competitive in the market. The purpose of this research is to analyze the influence of: Perceived Quality, Perceived Risk, Perceived Value, Perceived Price, Advertisement, Packing, Store Image, Social Influence, Consumers' Attitude to Purchase Intention Indomaret private label products in Jakarta. Data were obtained by distributing questionnaires to 350 respondents who met the criteria. Then the data were analyzed by classical assumption test, $\mathrm{F}$ test, $\mathrm{t}$ test, and analysis of the coefficient of determination. These results indicate that the Variable Perceived Quality, Perceived Risk, Perceived Value, Perceived Price, Advertisement, Packing, Store Image, Influence and Consumers' Attitude have a significant influence on Purchase Intention. Whereas Social Influence does not have a significant influence on Purchase Intention. Suggestion for research is that further research can be conducted with larger samples and different and more specific independent variables.
\end{abstract}

Abstrak : Bisnis ritel Indonesia telah berkembang dengan meningkatnya jumlah pengecer yang ada. Kehadiran pengecer ini memunculkan produk private label di Indonesia. Private label adalah salah satu strategi pengecer untuk menjadi kompetitif di pasar. Tujuan dari penelitian ini adalah untuk menganalisis pengaruh : Perceived Quality, Perceived Risk, Perceived Value, Perceived Price, Advertisement, Packing, Store Image, Social Influence, Consumers' Attitude terhadap Purchase Intention produk private label sirup indomaret di kota Jakarta. Data diperoleh dengan menyebarkan kuisioner kepada 350 responden yang memenuhi kriteria. Kemudian data dianalisis dengan uji asumsi klasik, uji F, uji t uji, dan analisis koefisien determinasi. Hasil ini menunjukkan bahwa Variabel Perceived Quality, Perceived Risk, Perceived Value, Perceived Price, Advertisement, Packing, Store Image, Influence dan Consumers' Attitude memiliki pengaruh yang signifikan terhadap Purchase Intention. Sedangkan Social Influence tidak memiliki pengaruh yg signifikan terhadap Purchase Intention. Saran penelitian adalah Penelitian selanjutnya dapat dilakukan dengan sampel yang lebih besar dan variabel independen yang berbeda dan lebih spesifik.

Keywords : Perceived Quality, Perceived Risk, Perceived Value, Perceived Price, Advertisement, Packing, Store Image, Social Influence, Consumers' Attitude, Purchase intention.

\section{PENDAHULUAN}

Private label adalah salah satu aktivitas peritel dalam memberikan nama atau merek pada beberapa item produk yang dijualnya. Levy dan Weitz (2012), menyatakan merek private label, juga disebut merek toko, atau merek sendiri, adalah produk yang dikembangkan oleh pengecer. Menurut Kotler dan Keller (2012:459) mendefinisikan private label yaitu : "Sebuah merek pribadi (juga disebut merek reseller, gudang, atau distributor) adalah merek yang pengecer dan 
grosir yang mengembangkan". Private label kini telah berkembang luas di Indonesia. Berdasarkan survei yang dilakukan Euromonitor tahun 2011, semakin banyak konsumen Indonesia yang menerima produk-produk private label. Hal ini disebabkan oleh dua faktor. Faktor yang pertama yaitu terjadinya peningkatan permintaan dari konsumen berpendapatan rendah hingga menengah terhadap produk private label yang harganya lebih terjangkau. Faktor yang kedua yaitu meningkatnya jumlah toko ritel moderen di banyak kota di Indonesia serta banyaknya promosi yang cukup agresif dari pemilik bisnis ritel untuk mendorong jalur private label. Promosi yang agresif ini mendorong pengenalan dan penerimaan yang lebih besar terhadap produk private label oleh masyarakat (Matahari Departement Store 2012).

Hasil survei (Nielsen, 2012) juga menyebutkan bahwa presentase pertumbuhan nilai jual Indonesia untuk private label melebihi $20 \%$ selama tahun 2011. Pertumbuhan produk private label bersamaan dengan pertumbuhan industri ritel moderen di Indonesia. Hal ini disebabkan private label menjadi salah satu strategi yang digunakan oleh ritel moderen untuk saling bersaing dalam meningkatkan pasar dan menyerap keuntungan lebih besar. Beberapa ritel moderen yang juga meluncurkan produk private label yaitu Giant Supermarket, Carrefour, Alfamart, Indomaret, Griya Mart, Superindo, Hypermart, dan Lottemart. Industri ritel moderen di Indonesia mengalami rata-rata pertumbuhan 10,8\% pada tahun 2015 dengan pertumbuhan tertinggi terjadi di segmen minimarket sebesar $11 \%$ dan supermarket/hypermarket sebesar 10,6\%. Penjualan toko moderen per kapita di Indonesia diperkirakan mencapai US\$ 60 dengan komposisi 56\% di minimarket dan 44\% di supermarket/hypermarket. Ukuran pasar industri minimarket di Indonesia mencapai sekitar 73 triliun rupiah dengan pertumbuhan rata-rata tahunan sebesar 13,5\% untuk periode 2012 - 2015. Persaingan yang ketat juga terjadi di segmen minimarket dan supermarket/hypermarket. Alfamart bersaing ketat dengan Indomaret. Sementara di segmen Hypermarket, Hero bersaing ketat dengan Hypermart (Dunia Industri 2015).

\section{TELAAH KEPUSTAKAAN}

Purchase intention adalah salah satu input utama yang digunakan oleh manajer pemasaran untuk memprediksi penjualan dimasa mendatang dan untuk menentukan bagaimana tindakan yang perlu diambil untuk mempengaruhi tingkah laku pembelian konsumen. Pada beberapa kasus, purchase intention biasanya digunakan untuk mengukur permintaan konsumen akan suatu produk baru menggunakan konsep dan tes produk Morwitz (2014:1).

Perceived Quality adalah kemampuan yang bisa dinilai dari suatu produk didalam menjalankan fungsinya, yang merupakan suatu gabungan dari daya tahan, keandalan, ketepatan, kemudahan pemeliharaan serta atribut-atribut lainnya dari suatu produk (Kotler dan Amstrong, 2014).

Perceived Risk adalah sebuah ketidakpastian yang dihadapi konsumen ketika mereka tidak dapat meramalkan konsekuensi dimasa yang akan datang atas keputusan pembelian yang mereka lakukan (Suresh A.M. dan Shashikala R., 2011).

Perceived Value merupakan penukaran yang menjadi pokok dalam pemasaran dengan nilai sebagai pengukur yang tepat dari penukaran apapun baik pantas maupun tidak (Kotler dan Keller, 2012).

Perceived Price adalah pandangan atau persepsi mengenai harga bagaimana pelanggan memandang harga tertentu (tinggi, rendah, wajar) mempengaruhi pengaruh yang kuat terhadap maksud membeli dan kepuasan membeli (Schiffman dan Kanuk, 2010).

Advertisement adalah semua bentuk terbayar dari persentasinonpersonal dan promosi ide, barang atau jasa melalui sponsor yang jelas melalui media cetak (Koran, dan majalah), media penyiaran (radio dan televisi), media jaringan (telepon, kabel, satelit, wireless), dan media elektronik (rekaman suara, rekaman video, CD-ROM, halaman website), dan media pameran (Billboard, papan petunjuk jalan, dan poster)" (Kotler dan Keller, 2012: 500). Pentingnya kemasan dan desain kemasan untuk memenuhi kriteria multi-fungsi yang berkaitan dengan 
logistik dan pemasaran dalam rantai pasokan yang diakhiri di tangan konsumen sehingga memunculkan fenomena perubahan pola konsumsi dan kebiasaan yang membutuhkan solusi kemasan yang inovatif di gerai ritel (Rundh, 2011).

Store Image adalah bagian vital dari komunikasi pemasaran dan penyampaian identitas perusahaan, karena citra toko mampu mempengaruhi persepsi konsumen (Preez dan Vyver, 2010).

Social Influence dipengaruhi oleh faktor-faktor sosial yakni seperti keluarga, kelompok serta peran dan status sosial (Kotler dan Armstrong, 2014).

Consumer's attitude terdiri dari 3 hal yaitu : Trust, Familiarity, Perceived Economic Situation. Trust merupakan komponen kognitif dari faktor prikologis. Kepercayaan berhubungan dengan keyakinan, bahwa sesuatu itu benar atau salah atas dasar bukti, sugesti, otoritas, pengalaman dan intuisi (Kotler dan Keller, 2012: 125). Familiarity adalah banyaknya pengalaman yang telah dikumpulkan oleh konsumen terkait dengan suatu produk atau merek (Alba dan Hutchinson, 2010). Perceived Economic Situation pilihan produk sangat dipengaruhi oleh keadaan ekonominya. Keadaan ekonomi terdiri dari pengahasilan yang dapat dibelanjakan (tingkat, kestabilan, pola waktu), tabungan dan aktiva (presentase yang lancar/likuid), hutang kemampuan untuk meminjam dan sikap atas belanja atau menabung.

\section{Kaitan antar Variabel}

\section{Pengaruh Perceived Quality terhadap Purchase Intention}

Schiffman dan Kanuk (2010) menyatakan bahwa persepsi kualitas adalah penilaian konsumen terhadap kualitas barang atau jasa yang berdasarkan informasi yang diterima berdasarkan asosiasi terhadap produk tersebut. (Kotler dan Amstrong, 2014) kualitas suatu produk adalah kemampuan yang bisa dinilai dari suatu produk didalam menjalankan fungsinya, yang merupakan suatu gabungan dari daya tahan, keandalan, ketepatan, kemudahan pemeliharaan serta atribut-atribut lainnya dari suatu produk. Dalam kasus ini yang termasuk sebagai kualitas produk adalah rasa, bau, kebersihan, dan kesegaran.

$\mathrm{H}_{1}$. Perceived Quality berpengaruh signifikan terhadap Purchase Intention.

\section{Pengaruh Perceived Risk terhadap Purchase Intention}

Schiffman dan Kanuk (2010) mendefinisikan risiko sebagai ketidakpastian yang di hadapi oleh konsumen ketika mereka tidak dapat meramalkan dampak dari keputusan pembelian mereka. Liljander (2009) menjelaskan bahwa setiap tindakan konsumen akan memberikan sebuah konsekuensi yang tidak akan dapat diantisipasi dengan perkiraan tertentu.

$\mathrm{H}_{2}$. Perceived Risk berpengaruh signifikan terhadap Purchase Intention.

\section{Pengaruh Perceived Value terhadap Purchase Intention}

Produk dikatakan memiliki nilai yang tinggi jika sesuai dengan kebutuhan, keinginan, dan permintaan pelanggan (Kotler dan Keller, 2012). Menurut McDougall dan Levesque (2010) Nilai yang dirasakan (perceived value) merupakan akibat atau keuntungankeuntungan yang diterima pelanggan dalam kaitannya dengan total biaya.

$\mathrm{H}_{3}$. Perceived Value berpengaruh signifikan terhadap Purchase Intention.

\section{Pengaruh Perceived Price terhadap Purchase Intention}

Munusamy dan Wong (2008) membuktikan bahwa ada hubungan positif yang signifikan antara harga dan motif konsumen terhadap pembelian produk private label. Oleh karena itu, sebagian besar konsumen akan membuat keputusan dengan merujuk pada produk dengan harga murah (Boutsouki et al., 2008).

$\mathrm{H}_{4}$. Perceived Price berpengaruh signifikan terhadap Purchase Intention.

\section{Pengaruh Advertisement terhadap Purchase Intention}

Iklan bertindak sebagai komunikator di mana ia menginformasikan konsumen tentang produk dan layanan (Uusitalo, 2011). Kim dan Parker (2009) mengemukakan bahwa sulit untuk mengukur keberhasilan iklan produk private label dan iklan yang sukses sering kali 
disertai dengan citra yang baik (Steinberg, dan Jules, 2011). Pernyataan ini sejalan dengan penelitian sebelumnya yang dilakukan oleh Liljander et al. (2009) yang mengungkapkan bahwa citra toko memengaruhi niat pembelian konsumen pada produk private label.

$\mathrm{H}_{5}$. Advertisement berpengaruh signifikan terhadap Purchase Intention.

\section{Pengaruh Packing terhadap Purchase Intention}

Menurut Kotler dan Keller (2012), kemasan yang baik dapat membangun ekuitas merek dan mendorong penjualan. Pengemasan penting karena menjangkau hampir semua konsumen, oleh karena itu merupakan faktor penting dalam proses pengambilan keputusan, dan konsumen biasanya memeriksa produk dengan melihat informasi yang diberikan pada pengemasan (Ampuero dan Vila, 2010).

$\mathrm{H}_{6}$. Packing berpengaruh signifikan terhadap Purchase Intention.

\section{Pengaruh Storage Image terhadap Purchase Intention}

Preez dan Vyver (2010) yang menyatakan bahwa citra toko adalah bagian vital dari komunikasi pemasaran dan penyampaian identitas perusahaan, karena citra toko mampu mempengaruhi persepsi konsumen. Tang dan Lim (2008:132) citra toko adalah : "Citra toko juga dapat didefinisikan sebagai persepsi keseluruhan pembeli memiliki lingkungan toko. Ini adalah kepribadian toko".

$\mathrm{H}_{7}$. Storage Image berpengaruh terhadap signifikan Purchase Intention.

\section{Pengaruh Social Influence terhadap Purchase Intention}

Perilaku konsumen dipengaruhi oleh faktor-faktor sosial yakni seperti keluarga, kelompok serta peran dan status sosial (Kotler dan Armstrong, 2008:163). Perilaku masyarakat terkadang dipengaruhi oleh lingkungan sosialnya seperti teman sekantor ataupun tetangga sebelah rumah. Social influence atau pengaruh sosial merupakan sekelompok orang yang sama-sama mempertimbangkan secara dekat persamaan di dalam status atau penghargaan komunitas yang secara terus menerus bersosialisasi diantara mereka sendiri, baik secara formal dan informal (Schiffman dan Kanuk, 2008:229).

$\mathrm{H}_{8}$. Social Influence berpengaruh terhadap signifikan Purchase Intention.

\section{Pengaruh Consumers' Attitude terhadap Purchase Intention}

Chaniotakis et al. (2010) menyatakan bahwa 'cara berpikir' mempengaruhi niat pembelian konsumen serta persepsi situasi ekonomi. Sebuah studi menemukan bahwa, konsumen akan mencoba untuk menghemat lebih banyak uang dengan membeli produk private label selama krisis ekonomi dan begitu kondisinya berubah menjadi lebih baik; mereka akan beralih kembali ke merek yang mereka kenal (Conroy, 2010). Ini karena ketika produk itu akrab bagi seseorang; dia akan mendefinisikan produk dengan cara yang baik. Oleh karena itu, untuk membangun kepercayaan pada produk private label, pengecer harus membiarkan konsumen merasa percaya diri dengan produk mereka (Broadbridge dan Morgan, 2010). Kepercayaan pada produk private label dipengaruhi oleh manfaat yang dirasakan, yang berarti bahwa persepsi kualitas harga mempengaruhi sikap konsumen.

$\mathrm{H}_{9}$. Consumers' Attitude berpengaruh terhadap signifikan Purchase Intention

\section{METODOLOGI PENELITIAN}

Penelitian ini disusun untuk menguji hipotesis, yaitu penjelasan mengenai hubungan antar tiap variabel. Hubungan antar variabel yang diteliti adalah untuk mengetahui ada atau tidaknya pengaruh variabel independen dengan variabel dependen. Periode penelitian dilakukan mulai Januari 2019 sampai dengan Mei 2019.

Data yang digunakan dalam penelitian adalah kuantitatif dan sumber data dalam penelitian ini adalah data primer yang merupakan hasil kuesioner dari 350 pelanggan Indomaret di Jakarta. Data yang terkumpul akan dianalasis secara bertahap dengan dilakukan analisis statistik deskriptif terlebih dahulu, selanjutkan dilakukan pengujian statistik dengan uji distribusi normal dengan menggunakan uji Kolmogorov Smirnov Test. Tahap selanjutnya melakukan uji Heterokedastisitas dan Multikolinieritas. Kemudian melakukan Uji Hipotesi 
dengan menggunakan Uji Signifikansi Simultan (Uji F), Menurut Ghozali (2012 : 98) mengatakan bahwa uji statistik F pada dasarnya dilakukan untuk mengetahui kelayakan dari seluruh variabel independen yang digunakan dalam penelitian. Pengujian dilakukan dengan menggunakan significance level 0,05 . Koefisien Determinasi $\left(\mathrm{R}^{2}\right)$ dimaksudkan untuk mengetahui tingkat ketepatan yang paling baik dalam analisa regresi, hal ini ditunjukkan oleh besarnya koefisien determinasi $\left(\mathrm{R}^{2}\right)$ antara 0 (nol) sampai dengan 1 (satu). Jika koefisien determinasi nol berarti variabel independen sama sekali tidak berpengaruh terhadap variabel dependen. Dan Uji Parsial (Uji t), dasarnya menunjukkan seberapa jauh pengaruh satu variable/variabel penjelas/independen secara individual dalam menerangkan variasi variable / variabel dependen (Supranto, 2010:60).

\section{HASIL PENELITIAN DAN PEMBAHASAN}

Dalam penelitian ini menggunakan sembilan variabel independen: Perceived Quality, Perceived Risk, Perceived Value, Perceived Price, Advertisement, Packing, Store Image, Social Influence, Consumers' Attitude, dan satu variabel dependen yaitu Purchase Intention.

Tabel 1 hasil Uji Normalitas menggunakan Uji Kolmogorov Smirnov. Jika nilai Prob / Sign F $>0.05 \rightarrow$ Sebarannya bersifat normal dan Jika nilai Prob / Sign F $<0.05 \rightarrow$ Sebarannya bersifat tidak normal.

Tabel 1. Hasil Uji Normalitas Kolmogorov-Smirnov One-Sample Kolmogorov-Smirnov Test

\begin{tabular}{|ll|r|}
\hline & & $\begin{array}{c}\text { Unstandardized } \\
\text { Residual }\end{array}$ \\
\hline Normal Parameters & & 350 \\
& Mean & $0 \mathrm{E}-7$ \\
& Std. Deviation & 1.24171681 \\
Most Extreme Differences & Absolute & .069 \\
& Positive & .065 \\
Kolmogorov-Smirnov Z & Negative & -.069 \\
Asymp. Sig. (2-tailed) & & 1.294 \\
\hline
\end{tabular}

a. Test distribution is Normal.

b. Calculated from data.

\section{Pengujian Hipotesis}

Pengujian dilakukan dengan menggunakan Uji Simultan ( Uji F ), dengan kriteria sig > 0,05 maka Ho diterima. Dan sig < 0,05 maka Ha diterima. Pada tabel 3, diperoleh nilai sig sebesar 0,000. Karena nilai sig < 0,05 maka Ha diterima artinya CA, SI, PQ, PR, STORE, PV, PACK, ADV, dan PP secara simultan terhadap PI.

\section{Tabel 2. Hasil Uji Simultan ( Uji F )} ANOVA $^{\mathrm{a}}$

\begin{tabular}{|ll|l|l|l|l|l|}
\hline \multicolumn{1}{|c|}{ Model } & Sum of Squares & df & Mean Square & F & Sig. \\
\hline \multirow{2}{*}{1} & Regression & 2441.605 & 9 & 271.289 & 171.412 & $.000^{\mathrm{b}}$ \\
& Residual & 538.109 & 340 & 1.583 & & \\
& Total & 2979.714 & 349 & & & \\
\hline
\end{tabular}

a. Dependent Variable: PI

b. Predictors: (Constant), CA, SI, PQ, PR, STORE, PV, PACK, ADV, PP

Pada Tabel 3, nilai R square adalah 0,819 atau 81,9\%. Artinya variabel CA, SI, PQ, PR, STORE, PV, PACK, ADV, dan PP memberikan pengaruh sebesar 81,9\% terhadap PI. Sedangkan sisanya sebesar 64,7\% merupakan kontribusi variabel lain selain CA, SI, PQ, PR, STORE, PV, PACK, ADV, dan PP. 
Tabel 3. Hasil Uji Koefisien Determinasi $\left(\mathbf{R}^{\mathbf{2}}\right)$

\begin{tabular}{|l|r|r|r|r|r|}
\hline Model & \multicolumn{1}{|c|}{$\mathrm{R}$} & $\mathrm{R}$ Square & $\begin{array}{c}\text { Adjusted R } \\
\text { Square }\end{array}$ & $\begin{array}{c}\text { Std. Error of the } \\
\text { Estimate }\end{array}$ & Durbin-Watson \\
\hline 1 & $.905^{\mathrm{a}}$ & .819 & .815 & 1.25804 & 1.887 \\
\hline
\end{tabular}

a. Predictors: (Constant), CA, SI, PQ, PR, STORE, PV, PACK, ADV, PP

b. Dependent Variable: PI

Pada Tabel 4, hasil Uji Parsial (Uji t) Jika sig > 0,05 maka Ho diterima, dan Jika sig < 0,05 maka Ha diterima.

Tabel 4. Hasil Uji Parsial (Uji t)

\begin{tabular}{|c|c|c|c|c|c|c|}
\hline \multicolumn{2}{|r|}{ Model } & \multicolumn{2}{|c|}{ Unstandardized Coefficients } & \multirow{2}{*}{$\begin{array}{c}\text { Standardized } \\
\text { Coefficients } \\
\text { Beta }\end{array}$} & \multirow[t]{2}{*}{$\mathrm{t}$} & \multirow[t]{2}{*}{ Sig. } \\
\hline & & B & Std. Error & & & \\
\hline \multirow{10}{*}{1} & (Constant) & -4.125 & .581 & & -7.100 & .000 \\
\hline & PQ & .193 & .015 & .340 & 13.047 & .000 \\
\hline & PR & .227 & .032 & .236 & 7.000 & .000 \\
\hline & PV & .342 & .059 & .184 & 5.795 & .000 \\
\hline & PP & .143 & .028 & .182 & 5.131 & .000 \\
\hline & ADV & .090 & .043 & .069 & 2.075 & .039 \\
\hline & PACK & .161 & .031 & .160 & 5.138 & .000 \\
\hline & STORE & .698 & .054 & .358 & 12.961 & .000 \\
\hline & SI & -.040 & .027 & -.041 & -1.503 & .134 \\
\hline & $\mathrm{CA}$ & -.073 & .013 & -.163 & -5.657 & .000 \\
\hline
\end{tabular}

Variabel PQ memiliki nilai sig sebesar 0,000. Karena nilai sig nya $<0,05$ maka Ha diterima artinya terdapat pengaruh dari PQ terhadap PI. Variabel PR memiliki nilai sig sebesar 0,000. Karena nilai sig nya $<0,05$ maka Ha diterima artinya terdapat pengaruh dari PR terhadap PI. Variabel PV memiliki nilai sig sebesar 0,000. Karena nilai sig nya $<0,05$ maka Ha diterima artinya terdapat pengaruh dari PV terhadap PI. Variabel PP memiliki nilai sig sebesar 0,000. Karena nilai sig nya $<0,05$ maka Ha diterima artinya terdapat pengaruh dari PP terhadap PI. Variabel ADV memiliki nilai sig sebesar 0,039 . Karena nilai sig nya $<0,05$ maka Ha diterima artinya terdapat pengaruh dari ADV terhadap PI. Variabel PACK memiliki nilai sig sebesar 0,000 . Karena nilai sig nya $<0,05$ maka Ha diterima artinya terdapat pengaruh dari PACK terhadap PI. Variabel STORE memiliki nilai sig sebesar 0,000. Karena nilai sig nya $<0,05$ maka Ha diterima artinya terdapat pengaruh dari STORE terhadap PI. Variabel SI memiliki nilai sig sebesar 0,134 . Karena nilai sig nya $>0,05$ maka Ho diterima artinya tidak terdapat pengaruh dari SI terhadap PI. Variabel CA memiliki nilai sig sebesar 0,000. Karena nilai sig nya $<0,05$ maka Ha diterima artinya terdapat pengaruh dari CA terhadap PI.

\section{KESIMPULAN DAN SARAN}

Hasil penelitian ini menunjukkan bahwa Variabel Perceived Quality, Perceived Risk, Perceived Value, Perceived Price, Advertisement, Packing, Store Image, Influence dan Consumers' Attitude memiliki pengaruh yang signifikan terhadap Purchase Intention. Sedangkan Social Influence tidak memiliki pengaruh yg signifikan terhadap Purchase Intention.

Variabel penelitian Perceived Quality, Perceived Risk, Perceived Value, Perceived Price, Advertisement, Packing, Store Image, Social Influence dan Consumers' Attitude dapat dikaji dengan variabel lain untuk memperkaya pengetahuan dan penemuan hasil yang baru mengenai variabel yang dapat mempengaruhi Purchase Intention. Penelitian selanjutnya dapat dilakukan dengan sampel yang lebih besar dan variabel independen yang berbeda dan lebih spesifik. 


\section{DAFTAR PUSTAKA}

Alba, J. W. and Hutchinson, J. W. (2010). Dimensions of consumer expertise. Journal of Consumer Research, 13, 411-454.

Ampuero, O., and Vila, N. (2010). Consumer perceptions of product packaging. Journal of Consumer Marketing. Vol. 23(2). pp. 100-112.

Broadbridge, A. and Morgan, H.P. (2010), Retail-brand baby-products: what do consumers think? Brand Management, Vol. 9 No. 3, pp. 196-210.

Chaniotakis, I.E., Lymperopoulos, C., and Soureli, M., (2010). Consumers' intentions of buying own-label premium food products. Journal of product and Brand Management. Vol 19(5). pp.327-334.

Conroy. P. (2010). Brand loyalty and the impact of private label products. Deloitte Debates, Available from: http://www.deloitte.com/us/brandloyalty. [Accessed 7th March 2011].

Frontier Consulting Group. (2016) Top Brand Award Kategori Ritel Hypermarket, Supermarket dan Minimarket. FCG [Internet]. [diunduh2016Apr4]. Tersedia pada: http://www.topbrand award.com

Ghozali, Imam. (2012). Aplikasi Analisis Multivariate dengan Program IBM SPSS. Yogyakarta: Universitas Diponegoro

Kim, N. and Parker, P. (2009). Collusive conduct in private label markets. Int. J.Res. Market. Vol. 16(2). pp.143-155.

Kotler, Philip and Gary Armstrong. (2014), Principles of Marketing, 15th Edition, New Jersey: Pearson Pretice Hall.

Kotler, P., and Keller, K.L. (2012). Marketing Management, Global Edition. Pearson Prentice Hall.

Levy, Michael and Weitz, Barton. (2012) Retailing Management, $8^{\text {th }}$ Edition. New York: The McGraw-Hill.

Liljander, V., Polsa, P., and Riel, A llard. (2009). Modeling Consumer Responses to an Apparel Store Brand : Store Image as a Risk Reducer. Journal of Retailing and Consumer Service, 16 (4). pp. 281-290.

Morwitz, Vicki (2014). Consumer's Purchase Intentions and their Behavior Foundations and Trends in Marketing Vol. 7 No.23 (2012). h.1.

Munusamy, J. and Wong, C.H. (2008). Relationship between marketing mixstrategy and consumer motive: an empirical study in major Tesco stores. UNITAR E-Journal. Vol.4(2).

Nielsen. (2012). Report 2012 Asia Pacific Ritel and Shopper Trends. [Internet]. [diunduh2016Feb13]. Tersedia pada: http://www.nielsen.com/ us/en/insights/news/2012/report-2012-asia-pacific-ritel-and-shopper-.html.

Preez, R. du and J. van der Vyver. (2010). Managerial and Consumer Perceptions of Apparel Store Image: A Congruity Analysis, Management Dinamics, Vol 19 No 1.

Rundh, B. (2011). The multi-faceted dimension of packaging. British Food Journal, Vol. 107 (9), pp. 670-684.

Schiffman and Kanuk. (2010). Consumer Behavior, Prentice Hall International, Inc, New York.

Steinberg and Jules. (2011). Good detail promotions don't cost much but they pay. This week in consumer electronics. Vol. 16 (3). pp. 30

Supranto J., (2012), Metode Riset dan Aplikasinya Dalam Pemasaran, Rineka Cipta, Jakarta.

Suresh and Shashikala. (2011). A Survey of the Effect of Consumers' Perceived Risk on Purchase Intention in E-Shopping. Business Intelligence Jurnal.

Uusitalo, O. (2011). Consumer perceptions of grocery retail formats and brands. Int.J. Retail Distrib. Manage. Vol. 29(5). pp.214-225 